\title{
Reabilitando o Positivismo: Francisco Rüdiger "critica" a Nova Teoria da Comunicação. Mas não impunemente ${ }^{1}$
}

\author{
Rehabilitating Positivism: Francisco Rüdiger "criticizes" the New Theory \\ of Communication. But not without being judged for it
}

\section{Ciro Marcondes Filho}

Pós-Doutorado, pela Universidade Stendhal de Grenoble, USG, França. Doutor em Sociologia da Comunicação, pela Universidade Johann Wolfgang Goethe, UJWG, Alemanha. Professor do Departamento de Jornalismo e Editoração da Universidade de São Paulo (USP) por mais de trinta anos. Criador da Nova Teoria da Comunicação.

\section{RESUMO}

Este texto é uma resposta ao artigo "A comunicação como aventura solipsística: sobre a "nova teoria" de Ciro Marcondes Filho", de Francisco Rüdiger. Esta análise examina alguns comentários a respeito da "Nova Teoria da Comunicação".

\section{PALAVRAS-CHAVE:}

Nova Teoria da Comunicação; Teorias das Comunicação; Crítica.

\footnotetext{
${ }^{1}$ Este artigo é uma publicação póstuma, finalizado em 31 de outubro de 2020.0 autor Ciro Marcondes Filho faleceu, aos 72 anos, em 08 de novembro de 2020, em São Paulo.
}

Dossiê Crise, Feminismo e Comunicação - https://revistaecopos.eco.ufri.br/ 


\section{ABSTRACT}

This text is an answer to the paper "Communication as a solipsistic adventure: about the" new theory "of Ciro Marcondes Filho", by Francisco Rüdiger. The analysis examines some comments about the "New Theory of Communication".

\section{KEYWORDS}

New Communication Theory; Communication Theories; Critique.

\section{Introdução}

O Sr. Francisco Rüdiger, eminente pensador da área de Comunicação em nosso país, resolveu voltar-se contra a Nova Teoria da Comunicação, realizando aquilo que em sua opinião seria uma crítica ao meu trabalho de 21 anos de investigação e pesquisas. E que eu saiba, há poucas investidas bem-sucedidas em nosso campo de atuação. A que me lembro com mais frequência foi a Resposta a John Lewis, nos anos de 1970, feita por Louis Althusser num livreto curto, o que fez com que aquele pensador caísse num buraco tão profundo, de onde jamais sairia, o que só valorizou seu criticado.

Muito saudável a empreitada de Rüdiger visto que em todo esse tempo nenhum pensador de calibre arvorou-se nessa aventura epistemológica, menos ainda propôs-se a lê-la em sua grande parte. Isso porque se trata, na leitura dos 7 volumes da série Nova Teoria da Comunicação, de um trabalho árduo, que exige paciência e dedicação algo estranho à maioria de nossos colegas que, em geral, optam por esquemas já prontos, bem arranjados, onde só falta inserir seu tema de pesquisa.

Sei também como é difícil "emplacar" algo novo na área (especialmente se for nacional, não importada do exterior), também porque as pessoas acostumaram-se com suas velhas teorias e não têm vontade nem coragem de embarcar em algo novo. Em geral, uma mesa de bar é um espaço mais adequado para fazer circular e ser aceito aquilo que está sendo propondo. 
É preciso muita paciência, perseverança, investimento e dedicação para conseguir furar essa parede de resistências e aceitar o novo. Às vezes são necessárias várias gerações para isso ou mesmo esperar que as pessoas morram para conseguir um certo sucesso.

Aqui é diferente. Do estudioso se exige certo calibre acadêmico ou intelectual próprio dos scholars, que se sentam numa mesa de biblioteca e escavam o que têm até o mais profundo naquilo que encontram.

Pois esse foi meu interesse desde que voltei ao Brasil no ano 2000, ir atrás daquilo que se denominou "pesquisa pura" para as Humanidades, ir a fundo para diagnosticar, afinal de contas, do que se trata quando alguém fala em comunicação. Apanhar um conceito e explorá-lo ao máximo, sugando toda sua potencialidade.

\section{0 conceito de comunicação como nós o vemos}

Mas, antes de mais nada, creio necessário rever meu conceito de comunicação porque parece que $o$ crítico $^{2}$ ainda não o entendeu. Em princípio, comunicação não tem nada a ver com (com)partilhamento, transmissão, transferência de algo. Pode-se passar um objeto a outra pessoa, uma fatia de pão, uma taça de vinho, uma caneta, um caderno, mesmo dinheiro. Mas não se pode repartir uma ideia, uma sensação, uma emoção. São objetos distintos.

Quando uma pessoa fala: "quero dividir com você essa sua dor", isso só pode ser uma metáfora, algo imaginário, porque a dor do outro não se sabe, não se pode saber. A pessoa apenas se solidariza porque passou por algo semelhante, ninguém sabe, de fato, o que o outro está sentindo.

Mas, além desse não compartilhamento, duas outras sensações podem ser sentidas dentro do mesmo conceito de comunicação: informação e sinalização. Por

\footnotetext{
2 Me é verdadeiramente incômodo escrever um réplica a Francisco Rüdiger, já que ele foi, desde décadas atrás, um interlocutor privilegiado, com que passei várias vezes em longas conversas em torno da mesa de um bar, discutindo questões comunicacionais das mais diversas. Hoje estou nesta situação pouco favorável tendo que replicá-lo num texto como o dele e criticá-lo falando da Nova Teoria da Comunicação. Pior ainda porque estou, no momento, em situação difícil de saúde, o que me levou a passar muito mais tempo do que imaginava elaborando, escrevendo e corrigindo um texto que merecesse esse interlocutor.
}

Dossiê Crise, Feminismo e Comunicação - https://revistaecopos.eco.ufri.br/

ISSN 2175-8689 - v. 23, n. 3, 2020

DOI: 10.29146/eco-pos.v23i3.27646 
exemplo, num certo momento eu passo em frente a uma grande aglomeração de rua e pergunto: “O que está acontecendo?” A resposta é: “um jogo de futebol, um clássico e há confusões lá dentro".

Se para mim isso é indiferente, eu sigo em frente. No caso de a confusão me causar algum interesse, eu digo que aquilo transformou-se em mim, tornou-se parte do meu ser, eu digo que ela "tornou-se informação".

Na verdade, aqui fizemos o percurso inverso da comunicabilidade. Primeiro, absorvemos o mundo à nossa volta. Sentimos as pequenas percepções de que falava Leibniz, que eram múltiplas e desorganizadas, mas, mesmo assim, responsáveis por aquilo que nós aqui denominamos sinalizações. A grande maioria das sinalizações não nos interessa, nós as desprezamos, sequer lhes damos atenção. Mas, quando algo nelas nos chama a atenção, nos atrai, elas tornam-se informação.

Observe-se que a informação aumenta minha dose de dados e referências sobre o mundo. Aumenta meu repertório. É o mesmo processo do jornalismo. Eu vou buscar saber, dar uma espiada no que está acontecendo lá fora. Ninguém me obriga ou força a isso. É um ato espontâneo e autônomo meu, jamais procurarei uma fonte - seja ela uma revista, um telejornal, uma página na internet, algo não dissonante com meus pensamentos, ideias, ideologias. A informação tem a função de conformidade, de manter as coisas como estão, não propor nenhuma alteração.

Diferente disso, mesmo oposta, é a função da comunicação: eu não vou buscá-la, ela abate sobre mim, me atropela, me arranca da passividade, tem uma função dissonante para minha vida, meu comportamento, minhas aspirações.

Isso era algo que o Sr. Rüdiger precisaria aprender, logo de início, antes de qualquer outra coisa. Caso contrário, toda argumentação cai por terra. Considerando isso, temos a primeira afirmação de Rüdiger (2020) que constato ser equivocada: "Isso ocorre com a própria experiência. Que critérios diz que estamos diante de um acontecimento comunicacional e não de qualquer outra situação mundana" (Rüdiger, 2020, p. 266).

Dossiê Crise, Feminismo e Comunicação - https://revistaecopos.eco.ufrj.br/ 
E ainda:

O evento poderia ser qualquer outro, um êxtase, um pavor, decepção, uma alegria. [...] 0 autor não teria como afirmar que tal evento único tem a ver com comunicação, que ele passa por alto, pois o acontecimento poderia ser revelação divina, insight psicológico, sinapse cerebral, acesso de loucura (Rüdiger, 2020, p. 268).

Não, não pode. Estamos diante de um acontecimento comunicacional e não diante de um acontecimento filosófico e os critérios saltam à vista, têm a ver com a descrição acima do que é comunicação. Minha afirmação é bem específica: um choque que nos violenta, que nos força a pensar. Os exemplos que Rüdiger nos traz são do acontecimento puro e simples do ponto de vista filosófico, não necessariamente de comunicação. Eventos filosóficos ocorrem o tempo todo.

\subsection{Do monólogo coletivo e matrizes}

Monólogo coletivo já é um desdobramento da comunicabilidade. No caso, diz Anders (1980), ocorre um inchamento, uma hipertelia informativa, em que a mesma informação circula em todos os ambientes formando uma espécie de viciosidade entre o público leitor que não tem a opção de receber o diferente.

Em verdade, há aí já bem mais do que dois critérios. Há o de Romano (2008), outro de Derrida (2006), mais um de Deleuze (2009), mais outro de Michel Serres (2001) e, por fim, um meu.

Entre a ocorrência de fatos e acontecimentos, podemos destacar dois tipos que podem se confundir: uns são ruidosos e barulhentos, escandalosos, pomposos, que são os casos naturais, sociais ou artificiais, que chamam atenção no contínuo mediático atmosférico. Constituem manchetes, notícias, produções jornalísticas estridentes e perturbadoras. Já, os segundos são casos de outra natureza. São silenciosos e sensíveis e atuam, no dizer de Claude Romano ${ }^{3}$, à margem de sua afetação, quer dizer, de sua representação, promovendo uma "reconfiguração

\footnotetext{
3 Para essa diferença, consultar ROMANO, Claude. Lo posible y el acontecimiento. Introducción a la Herméutica Acontecial
}

Dossiê Crise, Feminismo e Comunicação - https://revistaecopos.eco.ufri.br/

ISSN 2175-8689 - v. 23, n. 3, 2020

DOI: 10.29146/eco-pos.v23i3.27646 
anônima do mundo" (2008, p. 159), e ocorrendo num espaço "que uma palavra jamais pisou" enquanto algo que cai em cima de mim (Derrida et al, 2001, p. 95). Acontecimento filosófico x acontecimento comunicacional.

Gilles Deleuze, na obra Cinema 2 - Imagem e Tempo, de 1985, tampouco deixou de dar seu comentário sobre os fatos que nos alteram e que não são nem visíveis nem barulhentos ou estrondosos, mas que nos fazem pensar. Michel Serres (2001) fala de algo semelhante no livro Os cinco sentidos, quando comenta a algazarra de turistas no estádio grego, tirando-lhe a paz e a dedicação ao retiro e ao silêncio, que lhe traz essa passagem a outra dimensão.

E Heráclito é chamado para salvar a posição de Rüdiger:

Se é [com] a mudança de estado que das coisas [...] que define a ocorrência da comunicação [...] chega-se às causas toda vez que se deseja, salvo argumento específico em contrário, sempre está havendo alguma se partirmos de premissas heraclitianas [...](2020, p. 274).

Quer dizer, um tsunami nos abala, nos tira a paz, mas não é comunicação, pois não há um agente por traz dele interessado em comunicar. Apesar de Georges Bataille dizer que um êxtase é comunicação, ele não cabe na nossa definição. Menos ainda o pavor, a decepção, a alegria. Eventualmente, um insight psicológico poderia sê-lo.

Agora, apelar para Heráclito nos remete a um erro de base. A proposta não tem individualmente nada a ver. Este diz apenas que calor torna-se frio, seco torna-se úmido etc. É a alternância entre contrários e somente mudança e movimento, para ele, são reais; tudo vira fogo e fogo vira todas as coisas. Temos aí, portanto, uma dialética de inversões sem nada de qualitativo que a preencha.

A linguagem efetivamente morre. São os casais entediados um do outro, em que cada fala já é neutralizada pelo outro que sequer a ouve. São todos os relacionamentos em que a existência viva do outro foi substituída por uma imagem congelada, morta, seca e tórrida desse mesmo outro. Não se ouve mais a pessoa. 0 ouvido fechou-se.

Dossiê Crise, Feminismo e Comunicação - https://revistaecopos.eco.ufrj.br/ 
Todos partilham das mesmas emoções. E nisso não está de todo errado. Diz Günther Anders (1980) que quando as coisas distantes chegam muito perto, o próximo fica muito longe ou se apaga, que quando o fantasma se torna real, o real vira fantasmagórico. Ocorre, portanto, uma inversão: assimilamos o mundo distante dentro de nossas casas, ele se torna próximo e íntimo, ao mesmo tempo que assimilamos o mundo distante, atrofiamos aquilo que era íntimo em nossa sala de estar e que possuíamos antes da TV. Nossa intimidade interior fica assim, fantasmática. Segundo Anders (1980), os aparelhos roubam nossa capacidade de expressão, nossa potencialidade linguística, nossa vontade de falar; diante deles, emudecemos.

Naturalmente, um discurso como este, proferido em 1972, perde um pouco de sua validade 50 anos depois, especialmente porque as pessoas não vivem mais num espaço comunicacional fechado, mas vão buscar e repassar as informações recebidas por meio de seus telefones celulares, tablets e notebooks, sendo verdade ou não, introduzindo a variedade da pós-verdade nas trocas informacionais.

\subsection{Metáporo}

O uso do termo "método", criticado por Heidegger (1981), em O defeito dos nomes sagrados (Der Fehl heiliger Namen: Le défaut des noms sacrés, 1981), que o vincula à era tecnológica, a Descartes, à afirmação do sujeito como vontade (Cf. Heidegger, 1981, p. 95), deve ser trocado por um caminho do pensamento; para nós, por um metáporo. O caminho, diz Heidegger (1981) aí, não conhece procedimento, não conhece mediação. E, neste caso, sublinha Sarah Kofman, nem mesmo a dialética platônica lhe satisfaz, visto ser ela também condenada por Heidegger (1981), por ser "de essência tecnológica”, subordinada a uma vontade prometeica de dominação. Não obstante, adverte ela, Heidegger, que falou que a essa essência teria começado com Descartes, não estaria percebendo que a frase do Banquete: "Não sou sábio, nem ignorante", rompe com esse pensamento. As situações aporéticas, conclui, não seriam aí "passagens ruins" sobre um caminho, 
mas, radicalmente outras, elas enaltecem antes um pensamento do caminho do que um do método.

Retornando a Kofman, seu conceito de poros, diferente da oficialidade de um odos, é essa abertura de uma passagem por uma extensão caótica, introduzindo vias diferenciadas, tornando possíveis outras direções no espaço. De uma forma poética, a autora fala que poros "dissipa a obscuridade que reina na noite das águas primordiais abrindo as vias por onde o sol pode levar a luz do dia e as estrelas traçar o céu de rotas luminosas das constelações". Ora, se o termo método é formado pela fusão de metá e odos, e significa o caminho a ser percorrido pela pesquisa e se nós nos recusamos a nos submeter a um "caminho estriado", contaminado pelo seu conteúdo, jamais neutro, propomos substituir odos por poros, pelas diferenciações feitas acima, e construir provisoriamente o termo metáporo (metá+poros) como caminho que se desbrava a si mesmo, como uma embarcação que abre, enquanto segue, sua própria rota. 0 procedimento da razão durante o caminho só se justifica se construir, na dinâmica do movimento, o próprio percurso enquanto investiga. E, se adicionamos saber a esse caminho, podemos falar também em matéporo.

Portanto, nada de "doutrina para aconselhamento alheio", como diz o crítico (Rüdiger, 2020, p. 274). Longe disso, usamos também a expressão "caminho do meio" para construir, como vimos atrás, o conceito de metáporo, um substituto para o termo método, que é impraticável para a investigação dos fatos comunicacionais apoiados na razão durante ou na produção em dependência.

Diferente das ciências positivas, o metáporo não analisa, não adota um ponto de vista sobre a coisa, não disserta sobre ela, mas busca captá-la no próprio objeto. É como a cor, diz Bergson (2009), em que eu me envolvo no alaranjado a partir de minha imersão nele, não o vendo como uma cor intermediária entre o vermelho e o amarelo.

Do ponto de vista tópico, poros sugere pele, poro, orifício de um canal, de uma glândula na superfície cutânea. De qualquer forma, passagem. Aqui ousamos 
um pouco mais, sugerimos poro como o próprio ato de cavar uma passagem. Construir uma passagem para o outro lado, cavar na superfície da água, no monte de grãos, abrindo no vento, atos que desfazem em seguida tudo que acabamos de abrir.

Metáporo supõe também um ato de permitir o acesso, de deixar entrar, de liberar, de hospedar o outro, de me atravessar. 0 próprio observador se "porifica" abrindo a corrente de água enquanto nada. Água que o preenche, que o perfura, que o atravessa como se ele fosse uma tela, que o dissolve nela. A integridade se dilui. Merleau-Ponty (1996) diria que nos desfazemos na carne do mundo. Tornamo-nos seres cartesianos em decomposição, em diluição, em desaparecimento, misturando-nos no tudo-envolvente, "onde toda unidade, individuação, identidade do ser abrem-se à danificação" (Oliveira, 2016, p. 4).

Metáporo, um caminho que se desbrava a si mesmo, embarcação que corta a água em dois flancos e segue sua rota sem traçado demarcado. Passagem livre e inesperada para o outro lado, mas também, passagem para o conhecimento, matéporo, epistemologia espontânea do saber comunicacional.

Do procedimento. Trata-se aqui de identificar a interação, o espírito que a envolve, o tipo de energia circulante na cena em que duas pessoas colocam-se lado a lado ou frente a frente no encadeamento de frases e de olhares, posturas, movimentos, suspiros e toda sorte de manifestações que fazem parte do momento do diálogo. Trata-se dessa "operação comum" de que fala Merleau-Ponty (1996), operação em que nos entregamos plenamente, em que nos abrimos, baixamos nossas defesas e permitimos que as falas do outro misturem-se aos nossos pensamentos, fertilizando-os. A natureza dessa atmosfera é diretamente responsável pela qualidade da comunicação que aí se desenvolve. 0 outro não é alguém que fabricamos em nossa fantasia, mas algo ou alguém que nos ocupa quando nos liberamos de nós mesmos, que realiza em nós essa operação de intervir em nossos pressupostos, alterando-os. 
Trata-se de um inédito modo de observação que acompanha a vitalidade do fenômeno e que se constrói em contiguidade com ele. Metáporo é o procedimento de pesquisa em que a atividade do pesquisador vai abrindo sempre novos caminhos, criando continuamente outras formas, sempre buscando um ajuste ao fenômeno que está sendo estudado, que é, por sua vez, eternamente mutante.

\subsection{Contínuo mediático atmosférico}

Rüdiger confunde continuamente esfera pública com o contínuo mediático atmosférico, que é a ocupação da esfera política, ideológica e cultural de um contexto histórico específico com bombardeamento de informações direcionadas. O contínuo aqui é tanto o espaço onde a batalha se trava como o movimento que lá se realiza. O contínuo é "mediático" porque sua energização é realizada diariamente, o tempo todo, com meios de comunicação clássicos, assim como nas redes sociais. Já, a noção de "continuidade" fala de um momento bem particular, com ataques sequenciados e ininterruptos, e dele seguir por espaços lisos. E é "atmosférico" porque constrói atmosferas próprias específicas ad hoc, igualmente transitórias. Logo, consciência coletiva (Durkheim), noosfera, esfera pública, superestruturas sociais, que têm caráter estático, não cabem no conceito de tempo contínuo mediático, trabalha-se intensamente durante certo período para efetivação de mudanças parciais ou totais no Estado.

A construção da contínua atmosfera mediática foi uma estratégia surgida por força da expansão dos processos tecnológicos de informação (a imprensa, rádio) num momento em que grandes contingentes sociais urbanos, constituídos a partir da industrialização que se impôs em todos os países europeus, aglomeramse nas metrópoles e ganharam, com isso, a implantação do voto universal, inigualável poder de barganha.

A expansão do nacional-socialismo ocorreu em solo já trabalhado pelo movimento para acolher esse discurso de autodestruição das próprias massas. A crise da bolsa de valores americana, associada à cobrança das dívidas de guerra 
acelerou o clima favorável ao hitlerismo. A máquina fascista, então, teve pouco trabalho em dar o golpe e surgir como partido único. 0 que Goebbels, Ministro da Propaganda na Alemanha Nazista, fez foi unificar o contínuo, reunindo todas as forças políticas e ideológicas em torno dessa atmosfera mediática de contínua injeção de frases que exigiam engajamento radical.

No pós-guerra, o regime foi eliminado, mas não as estratégias de controle a ele associadas, que acabaram por alimentar a máquina de propaganda da Guerra Fria e, mais recentemente, das guerras ideológicas de produção de fake news e de desinformação.

A esfera política "joga iscas" no contínuo mediático atmosférico visando repercussões de seus movimentos da esfera pública. Eventualmente, como dizia o personagem Conrad Bream (Robert de Niro), em Mera Coincidência, (Wag the Dog, Barry Levinson, 1997), a imprensa "morde a isca". No Estado fascista alemão, a esfera política e a esfera econômica subsumiam-se ao contínuo atmosférico, onde dominou o paroxismo. Nas situações de democracia atuais, a esfera política tenta permanentemente obter vantagens estratégicas e pontuais no jogo de forças do contínuo mediático, da mesma forma como a esfera econômica busca construir para si condições favoráveis por meio do trabalho de relações públicas (cuidados com a imagem, produção de releases) e de seus investimentos publicitários. Os chamados "três poderes" não possuem a força e a determinação que se supõe (o poder do Estado expressa-se apenas pelo poder de polícia, de coerção) e a comunicação, em realidade, o contínuo mediático, atua como esfera dominante e determinante, apesar de não ser dirigida explicitamente por ninguém, de ser uma nebulosa de funciona apenas como corpo sem órgãos de tudo que lhe bate.

Em episódios totalitários ou de exceção, a instância reguladora busca encampar o processo livre e incontrolável do contínuo mediático, submetendo-o a padrões de mobilidade reduzida, inflexíveis, travados, "sintonizados". Nos regimes democráticos, esse comportamento do sistema regulador se afrouxa e este age em 
geral a posteriori coibindo abusos, controlando usos, exercendo uma função ordenadora.

O contínuo atmosférico não existe "em si", não é uma entidade, "um corpo", algo que seja dotado de um estatuto ontológico determinado; trata-se, antes, de um fluxo, um contínuo de energias e de humores, instância paradoxal, fator imprevisível e incontrolável, agente de uma quase-causa e produtor de efeitos reais.

Opinião pública é uma forma que se constitui a partir de um médium disperso e amplo, ou, então, um arranjo eventual, transitório, conjuntural, de um conjunto disperso de indivíduos a partir de um certo tema que domina o contínuo mediático. Uma união fraca de elementos superabundantes que leva, em épocas específicas, à constituição de uma união forte de caráter passageiro (Luhmann, 2005).

A comunicação virtual disputa espaço no contínuo mediático atmosférico. Isso porque o contínuo mediático é vapor, nuvem, uma neblina envolvente carregada de ondas, de movimentos, de fluxos, de temas que se digladiam para ocupar o melhor espaço e, neste quadro, as contribuições da internet são também descargas no contínuo atmosférico. Tornam-se temas, são polêmicas, evocam discussões, criam sentidos. A diferença é que já não partem de instituições visíveis e localizáveis no espaço, como são as emissoras, as estações, as empresas de publicação e de edição; são derivações virtuais destas ou emanações livres que partem da massa indistinta de singularidades (de indivíduos) e dos sistemas desreguladores. Não há grandes diferenças, pois, por ter a vocação de incorporar toda a produção social, o contínuo recebe também injeções desse tipo da rede.

Cada informação veiculada no contínuo mediático é uma efetuação, uma singularidade. Por força do incorpóreo (neste caso: o interesse; em outro caso poderia ser a moral, o desejo, o enaltecimento cívico), as ocorrências singulares rebatem sobre a superfície metafísica, do Acontecimento, que retorna às pessoas agora como eterno retorno.

Dossiê Crise, Feminismo e Comunicação - https://revistaecopos.eco.ufri.br/

ISSN 2175-8689 - v. 23, n. 3, 2020

DOI: 10.29146/eco-pos.v23i3.27646 
O fato ganhou outra dimensão, "emplacou" como "o" evento da temporada. É aquele espírito que um escritor busca capturar além da mera transcrição jornalística. Rotineira. Stendhal, Victor Hugo, Tolstói descrevem uma batalha, esta os sobrevoa, ela é um "neutro" em relação às descrições, tempo em estado puro.

\section{Bergsonismo $\mathrm{x}$ fenomenologia}

“Devemos pensar em movimento, produtor de teorias do 'durante', sugerir descrições ou constatações que considerem a provisoriedade do saber" (Marcondes, 2010a, p. 247). “Disso resulta uma doutrina exotérica, de corte arbitrário e feições dogmáticas" (Rüdiger, 2020, p. 265).

Henri Bergson (2009) significa, como os autores anteriores, uma crítica à ciência empírica, à dialética hegeliana e ao idealismo kantiano, mas, também, ao psicologismo, particularmente de William James. A crítica da ciência em geral é realizada por Bergson a partir da discussão das categorias de tempo e espaço. No campo da psicologia, o filósofo investe contra a psicofísica de Fechner.

0 bergsonismo e a fenomenologia de Husserl são proposições epistemológicas que se aproximam e que se separam. Estão próximas no sentido de ambas afirmarem que as coisas não são percebidas na consciência, mas ali, onde estão, no mundo. Para perceber as coisas, diz Bergson (2009), nos colocamos nelas, entramos em seu movimento. O conflito está, segundo Deleuze (2009), na posição da consciência. Nenhum dos dois aceita a visão de mundo da psicologia de sua época, que colocava as imagens no interior da consciência e o movimento dentro do espaço, sem explicar como se passava de um para o outro. 0 problema, portanto, era de romper com essa dualidade imagem/movimento, consciência/coisa, e encontrar o entrecruzamento desses dois campos. E aqui diferem as posições. Para Husserl, toda consciência é consciência de qualquer coisa; para Bergson (2009), “toda consciência é qualquer coisa” (Deleuze, 2009, p. 93). 
Rüdiger efetivamente desconhece Bergson. É uma pena visto que se trata de um autor que dá exatamente esta resposta esperada, que é pensar em movimento, no 'durante'. Mas isso ainda é muito estranho para nosso crítico, que chama Bergson de exotérico, dogmático. Iria cair sob uma chuva de protestos e ridicularizações que o inibiriam forever na crítica da comunicação.

Vamos esboçar o que para nós é o projeto de Bergson, assim como, derivado disso, seriam suas teses fundadoras. Seu Projeto, sinteticamente, seria o de "despertar a crisálida", restituir ao movimento sua dinâmica e evitar que se tomem as petrificações conceituais em lugar dos processos e acontecimentos que lhes dão origem. Para ele, só existe o movimento, nada mais que o movimento. Esse Projeto tem um método, o da intuição. Deleuze (2009) via contradição no fato de um método poder apoiar-se na intuição, já que esta é imediata, instantânea, enquanto aquele exige mediações. Mas Bergson (2009) não duvida, diz que a simplicidade não exclui uma multiplicidade qualitativa e virtual.

O monopólio do discurso vai perdendo terreno para outros códigos, o sistema da escrita entra em crise com o início do armazenamento técnico de dados, a vitória da matemática sobre o caráter conceitual e especulativo do conhecimento anterior. É o que Henri Bergson criticava como a dilaceração da percepção “a física opera com uma decomposição infinita do tempo" (2009).

0 problema da forma proposta pela etnologia é o deste segundo tipo de saber, da aspiração de se estar fazendo ciência sem aspas, ou seja, a crença na existência de uma verdade, mesmo que inatingida pelo homem, mas buscada pela ciência, como dizia Nietzsche na segunda afirmação da História de um erro: "o verdadeiro mundo, inalcançável por ora, mas prometido ao sábio, ao devoto, ao virtuoso" (2006).

Para Henri Bergson (2009), a intuição é um conhecimento sui generis, comparável ao instinto e ao senso artístico, que nos revela aquilo que os seres são em si próprios, por oposição ao conhecimento discursivo e analítico, que nos faz conhecê-los do exterior. Segundo ele "Chama-se intuição a esta espécie de simpatia 
intelectual pela qual nos transportamos para o interior de um objeto para coincidir com aquilo que nele existe de único e, por consequência, de inexprimível" (2009, p.).

Somos seres que possuem tristezas, paixões, emoções estéticas, alegrias. Todas elas manifestam-se por intensidades. Começam de forma mais ou menos fraca, em geral isoladamente, mas vão se expandindo aos poucos, tingindo com sua cor nossa realidade psíquica. É assim que o filósofo francês explica nossa percepção e a atenção que dela decorre. Quando um contínuo passa a ocupar um grande espaço na alma, sua imagem, diz ele, modifica percepções isoladas penetrando nelas e isso também acontece com a comunicação.

Nosso corpo percebe o mundo, mas há tantas sinalizações externas que não lhe interessam e que são simplesmente ignoradas. Elas apenas o atravessam. Mas há outras que convém ser captadas, constituindo nossas percepções. Intervimos, então, na coisa, praticamos um corte nesse volume de sinalizações. Nosso corpo, dessa maneira, funciona como uma central telefônica, sintetizando todo um conjunto de sensações e de movimentos. Mas isso acontece de forma impessoal.

Na percepção, que é o nome que Bergson (2009) atribui às sinalizações, meu corpo seleciona algo dos objetos externos. Em princípio, ele nada cria, apenas elimina as imagens nas quais não pode influir e, das demais, exclui as que não interessam. Para ele, isso se chama "percepção pura". Ela é seletiva, mas não há a figura de um ego decisor cartesiano. Nada se dá por intenção pessoal. A semelhança com as pequenas percepções de Leibniz é inegável. Seria Leibniz também dogmático e arbitrário? Certamente que sim, para Rüdiger.

Aos poucos a percepção adota o corpo como centro e toma nossa representação. Não é de mim que a coisa parte (como acham os psicólogos), antes devo eu me colocar no mundo. Quando ouvimos uma música, diz Bergson (2009), ela exprime um tipo de amor, não um amor determinado de uma pessoa, mas a "toda humanidade". 
A linguagem nos sugere que uma sensação seja invariável, com isso ela meio que "esmaga" as impressões delicadas e fugidias de nossa consciência individual. 0 mesmo acontece com outros sentimentos. Um amor profundo e uma melancolia invadem nossa alma, sua marca é de serem confusos, obscuros, incapturáveis. É aí que se concentra sua originalidade. Mas quando lhes damos um nome, um número, uma definição, a sua originalidade se deforma. É que o eu interior que sente, se apaixona, delibera e decide é uma força na qual penetram estados e modificações. Contudo, diante da vida social e da linguagem, que são mecanismos simbolizantes, impessoais, abstratificantes, esse eu fundamental acaba ficado ofuscado.

A pesquisadora norte-americana Barbara Kennedy (2002) não tem nada a ver com o bom, o romântico ou qualquer outra noção transcendente, mas com sentimentos como duração, movimento, processo contínuo, isto é, temporalidade e ritmo, não com o "choque estático" com excitações do sistema nervoso (Kennedy, 2002, p. 30-31). A sensação, assim, se manifesta com categorias como consonância, dissonância, harmonia em tom, linha, luz, cor e ritmo (Cf. 2002, p. 134).

\section{Luhmann}

O Sr. Rüdiger pergunta: "Qual é a base para o autor afirmar que a comunicação é rara, embora às vezes aconteça? Hipótese, dogma ou impressionismo? Que critério - sendo categorial - para não contradizer que a comunicação é sempre singular?" (Rüdiger, 2020, p. 9). Sim, ele tem razão em uma questão: a comunicação é rara. 0 dogma volta aqui novamente com o impressionismo. Tem razão, porque a comunicação é rara, estamos chegando perto da alethéia. Somos triunfantes de Platão. Afinal, passou a vida inteira procurando a verdade e ela estava aqui, bem perto da mão, para quem quisesse vê-la. É o que revela é Luhmann (2005) mas, juntamente com ele, Derrrida (2006).

Niklas Luhmann (2005), esse sociólogo alemão, passou a vida escrevendo. Criou um sistema relativamente esperto para demonstrar que comunicação é algo sumamente improvável. Filmes foram rodados para prová-lo (ou para reprová- 
lo?). Dúvida cruel. De qualquer maneira, vamos até ele para saber que essa eminência alemã, que ousou desafiar a sociologia estabelecida de Jürgen Habermas.

Nem todos os sociólogos, aliás, bem poucos, vão a campo para defender suas teorias. Na maioria das vezes as criam em laboratório e as submetem à sua categoria acadêmica ou intelectual para ver se há concordância. É o método observacional, amplamente utilizado em ciências humanas. Em Luhmann (2005), esse é um caso bem específico. Segundo sua teoria, os sistemas são em princípio fechados e apenas abrem uma fresta para observar o que acontece no meio ambiente. De lá extraem suas considerações, vindas das "irritações" de fora, e com elas se recompõem e mantêm sua vitalidade.

Luhmann (2005) critica as teorias da comunicação dizendo que elas são carregadas de metafísica. Isso quer dizer que ao se falar em comunicação está se pensando no transporte, no trânsito de coisas, que seriam esses comunicados. Ideias, conceitos, sensações seriam objetos transportáveis. Contra isso, ele afirma que a comunicação é algo altamente improvável e só aconteceria entre sistemas sociais. Mas, para salvar sua teoria, admite que há fórmulas que "furam" esse tipo de casco e que seriam os meios de comunicação simbolicamente generalizados. Na religião, quando o discurso não convence se apela para a fé. Na política, apela-se para o poder (o da "caneta"), na afetividade, para o amor, na ciência para o cientificamente comprovado. Então, você tem que buscar algo fora dessas categorias para legitimá-las como comunicação.

As teorias de Luhmann (2005) encontraram respaldo nos Estados Unidos, com a equipe da Cibernética de Segunda Ordem, especialmente com Heinz von Foerster e o biólogo Humberto Maturana. Para o primeiro, nem comunicação nem informação existem. E, para isso, não é preciso ir a campo para sabê-lo. Informação, porque é um processo relacional: somente o que me interessa é informação, não qualquer notícia de jornal, qualquer informe da TV, qualquer fato noticioso que quebra a normalidade. Já, a comunicação não existe porque não se 
pode transferir nada da mente de uma pessoa para outra. Pode-se tentar, mas o resultado é pífio.

\section{Maturana}

Com Maturana, o processo é ainda mais desenvolvido. Segundo ele, duas mentes não podem se comunicar porque se trata de sistemas complexos, fechados em si mesmos, e qualquer tentativa será falha, pois, segundo o esquema luhmanniano, cada corpo reage à sua maneira ao processo comunicacional. Um sujeito pode dizer A e o outro entenderá, mas responderá B, segundo sua própria lógica. Ele, como biólogo, o demonstra com a experiência com uma salamandra. Não importa a intervenção humana, o animal continuará a responder segundo sua determinação interna. Outro caso é o exemplo fictício de um homem dentro de um submarino que consegue manipular bem sua nave, desviar-se de todos os perigos, e, quando saudado pela sua perícia, argumenta que não, que não fez nada além de sua tendência natural, que é a de agir segundo seu próprio organismo o comanda.

\subsection{0 compartilhamento da comunicação e esta como "algo de natureza estética"}

E, no entanto, apesar dessa presença em toda parte, apesar do excesso de comunicação e, talvez mesmo, por causa dele, as pessoas de bom senso continuam a achar que não há compartilhamento, que não há troca, que é difícil passar ao outro o que a gente sente, como a gente sente as coisas que estão dentro da gente. As pessoas razoáveis continuam a achar que sua maneira de ver o mundo, seus sentimentos, suas angústias, suas alegrias são fatos internos, íntimos, incomunicáveis. Apesar do volume imenso de aparelhos postos à nossa disposição - televisão, internet, telefone celular, aparelhos de transmissão de fax, telões etc. a vida de cada um ainda é uma caixinha fechada, um universo oculto, um mundo trancado. 
Von Foerster e Luhmann (2005) não acreditam na comunicação, pois "caixas pretas" jamais vão se reconhecer, mas, se assim o fosse, não poderia haver compartilhamento de emoções, sensações, vivências que algumas formas estéticas, que certos "entendimentos tácitos", que certas "telepatias" viabilizam. Comunicar efetivamente é sentir junto, o mais denso e profundo que se possa imaginar. É seguramente um processo que se realiza em graus distintos de sucesso.

O objetivo do diálogo, acreditam eles, não é analisar as coisas, ganhar a discussão ou trocar opiniões. Seu propósito é suspender as opiniões e observá-las ouvir os pontos de vista de todos, suspendê-los e a seguir perceber o que tudo isso significa. Poderemos simplesmente compartilhar a apreciação dos resultados: e dessa totalidade a verdade emerge sem se anunciar, sem que a tenhamos escolhido.

O que acontece, então, que faz com a comunicação aproxime-se da relação estética? Walter Benjamin (2012) já nos aproxima desta relação em 1935, descrevendo política como estética:

Na época de Homero a humanidade oferecia-se em espetáculo aos deuses do Olimpo e agora ela faz de si mesma seu próprio espetáculo. Tornou-se suficientemente estranha a si mesma, a fim de conseguir viver sua própria destruição como um gozo estético de primeira ordem" e a outra: "esta é a estetização da política, tal como o pratica o fascismo (Benjamin, 2012).

\section{Kant e o compartilhamento}

Na questão estética, precisamos fazer um retrocesso a Kant (2008) para entender a comunicação. Enquanto o belo é lúdico como elemento estético e viceversa, como funciona um objeto estético como forma de comunicação? O sublime, para Kant (2008), opõe-se quase totalmente ao belo. Enquanto o belo é lúdico, é contemplação serena, tranquila, algo que se ama sem interesse, um certo prazer bem positivo e objeto de um afeto lânguido, o sublime, opostamente, pressupõe um abalo, uma seriedade, um prazer, mas pelos caminhos da negatividade. 0 sublime não comporta atrativos, ele é o que é. 0 objeto, indiferente a nós, como que "nos 
repele", provocando nossa inadequação a ele. Nós não o amamos, é diferente, nós o respeitamos, o levamos em consideração, nos acautelamos diante dele:

O sentimento do sublime é um prazer que surge só indiretamente, ou seja, ele é produzido pelo sentimento de uma momentânea inibição das forças vitais e pelo abalo imediatamente consecutivo e mais forte das mesmas, por conseguinte, enquanto comoção não parece ser nenhum jogo, mas seriedade na ocupação da faculdade da imaginação (Kant, 2008, p. 90).

Tabela 1: quadro comparativo

\begin{tabular}{|c|c|c|c|c|}
\hline & Kant & Barthes & Estético & Nova Teoria \\
\hline Não dissonante & Belo & prazer & arte popular & informação \\
\hline Dissonante & sublime & gozo, fruição & estético & comunicação \\
\hline
\end{tabular}

Fonte: Elaborado pelo autor.

E como se dá essa inadequação? Diante desse objeto, nossa faculdade imaginativa se crê apresentada a algo excessivo, que a supera "o quão pequeno em comparação com as ideias da razão [é] tudo o que a natureza contém de grande como objeto dos sentidos para nós" (Kant, 2008, p. 103-104). Sente-o como um abismo em que nos priva da liberdade. Mas esse excesso, diversamente, torna-se um desafio para a razão suprassensível. Por meio dele, a faculdade imaginadora se amplia e adquire um poder, ela assume esse sacrifício:

Aquilo que é uma privação, embora em favor da liberdade interna, descobre em nós, por outro lado, uma profundidade imperscrutável desta faculdade suprassensível, com suas consequências que se estendem até o imprevisível: assim, o sentir-se bem do lado estético (referido à sensibilidade) é negativo, isto é, contrário a esse interesse, mas, do lado intelectual, é considerado positivo e ligado a um interesse (Kant, 2008, p. 118).

Por aí se vê que no sublime se trata de um movimento da alma que é acrescido de um julgamento do objeto. Diante dele, do abalo que ele nos provoca, sentimos ao mesmo tempo atração e repulsa. Ele nos choca, nos causa uma 
sensação de desprazer, apresenta-se como violento e inapropriado e nós tememos nos perder nesse abismo.

Constata-se, assim, que o sublime, para Kant (2008), está antes nas ideias do que na própria natureza, que se coloca diante de nós dessa forma assustadora (2008, p. 96). Sublime é, portanto, uma maneira de pensar, quer dizer, ele se refere a "máximas para conseguir o domínio do intelectual e das ideias racionais sobre a sensibilidade" (2008, p. 120). É algo que está na alma daquele que julga, trata-se de uma disposição do espírito, de um certo entusiasmo e se refere ao uso que fazemos das coisas. Esse entusiasmo pode ser resumido como a tensão das forças por meio de ideias que impulsionam a alma (Kant, 2008, p. 119, grifo nosso).

Assim, com o sublime, estamos diante de um afeto vigoroso, algo que desperta a consciência de nossas forças e a conduz para vencer as resistências (como é o caso da cólera e mesmo do desespero, quer dizer, o desespero indignado, não o desencorajado, adverte Kant, (Kant, 2008, p. 119), “uma sensação oposta ao afeto lânguido do belo, cuja debilidade está exatamente nessa serenidade tranquila e imóvel, sentimento".

O prazer extraído do sublime, como visto, não é imediato. Inicialmente há uma certa inibição das forças vitais, elas ficam abaladas, precisam de um tempo, um tempo de incubação. Isso porque, diante do sublime, assim como diante do estranho, da alteridade, daquilo que nos suplanta, deparamo-nos com o impoder do pensamento. Mas essa é a própria lógica da comunicação, o fato de um primeiro choque, de um abalo, uma perda de solo, um deparar-se diante do abismo nos fazer ver o negativo como positivo, um salto de consciência, uma atração-repulsa, esse "entusiasmo" de que fala Kant (2008), que são as ideias que impulsionam a alma para vencer resistências.

Efetivamente não está no belo a força e a capacidade comunicativa; lá, só encontramos a tranquilização, a paz, a serenidade, o conforto, uma certa adequação do mundo àquilo que esperamos dele. É lúdico, como diz Kant (2008), é diferente do sério. Necessitamos, ao contrário, do embate, da confrontação para 
que se produza o novo, para que as ideias sofram um processo de reformulação, reorganização, refundação a partir do contato com o estranho, o incomensurável, o violento, o sublime, enfim.

Por fim, complementa José Gil (2005), o valor universal de uma obra é algo paradoxal. Não há a pretensão de assentimento universal, mas, ao contrário, é a "universalidade local e plural de cada um, seu gosto" o que garante seu valor (Gil, 2005, p. 217). Uma universalidade de novo tipo funda-se não na pretensão à universalidade de juízos, mas sua negação. É a afirmação do caráter subjetivo da imagem, segundo ele, que funda esse novo tipo de universalidade e não "a diferença tensa interna numa multiplicidade coletiva de pintores heterônimos" (Gil, 2005, p 272).

De certa maneira, essa "objetividade" estaria embutida no critério de compartilhamento universal kantiano, quando Kant (2008) diz que belo nunca é individual, que ele tem uma "universalidade objetiva", manifestada num estado de ânimo, num prazer ao se observar algo belo, exigindo que esse prazer tenha que ser compartilhado por todos, numa espécie de unanimidade, de que a sensação só é válida se compartilhada, e, por fim, justificando-a como "uma tendência natural à sociabilidade". Esse juízo, com o selo de "exemplar", Kant (2008) o torna uma obrigatoriedade geral, mesmo que suas bases sejam apenas intuídas, supondo, portanto, adesão compulsória a um padrão de gosto, que o filósofo irá chamar de dever ou lei.

O compartilhamento universal do gosto ocorreria na passagem do "nosso sentimento do belo" para um "sentimento comunitário do belo" e se realizaria através de regras em que o subjetivo-universal passa a exigir dos demais esse tipo de assentimento universal a essas mesmas regras. Vimos atrás que, para Kant:

Em todos os julgamentos pelos quais declaramos que algo é belo não permitimos a ninguém ser de outra opinião, sem com isso fundarmos nosso julgamento sobre conceitos, mas somente sobre nosso sentimento, o qual não colocamos como sentimento privado, mas como um sentimento comunitário social (Kant, 2008, p. 85). 
A suposta objetividade do compartilhamento geral do gosto não se sustenta uma vez reconhecida a crise do paradigma objetivista nas ciências, que veio com a teoria da incompletude de Gödel, da incerteza de Heisenberg e da indeterminação de Gil (2005), que passaram a duvidar das descrições imparciais e destacar o papel do observador no processamento da pesquisa. Com isso, afirmações como certo e errado, justo e injusto, belo e não belo deixam de se validar por juízos gerais e consensuais, visto que, para os pensadores da Cibernética de Segunda Ordem, "um organismo só entende, de fato, de seu próprio comportamento" e as avaliações externas só interessam aos próprios avaliadores. Vejamos isso mais de perto.

\section{Sobre o conceito de "compreensão" na filosofia e na comunicação}

Podemos supor que o acontecimento comunicacional esteja, portanto, mais no sublime (tomado no sentido metafórico) do que no belo, só que o sublime antilhano é geralmente atribuído a grandezas da natureza, e lá não há nenhuma intencionalidade comunicativa. Na comunicação, eu sou tocado, atingido, flechado, e, como resultado, deixo de ser o mesmo. Mas houve uma intenção de algum agente humano - em pessoa, nas suas obras ou em seus atos - que procurou a comunicação.

A preocupação com a língua é algo que tem uma longa história na filosofia. O filósofo Kant (2008) foi quem primeiro associou a emancipação à questão da linguagem ao vincular os pressupostos de autonomia e esclarecimento à escrita (por exemplo, a elaboração da Enciclopédia, por D'Alembert e Diderot é um monumento à escrita e à superação do obscurantismo), tornando-se este, instrumento por excelência do pensamento, da autonomia e da maioridade.

Também Adorno e Horkheimer, em sua Dialética do esclarecimento, recorrem a Kant para fundamentar sua concepção de autonomia. Para estes, a tarefa a ser realizada era a de superar a "imaturidade" da época (anos 40 do século passado) e de nos tornarmos indivíduos esclarecidos, quer dizer, "realmente 
autônomos". Ser autônomo, para eles, não é apenas sermos livres, mas podermos escolher e fixar metas para nós mesmos e desenvolver meios apropriados para esses fins. Igual caminho trilhou Habermas para construir seus conceitos de razão, linguagem e emancipação.

Sínteses a priori:

Nós conhecemos qualquer coisa a priori dos objetos [isto é: sem necessidade da experiência]. Mas, o quê? Kant responde distinguindo duas grandes faculdades do espírito humano: a sensibilidade e o entendimento. Pela primeira, os objetos nos são dados pelas intuições sensíveis; pelo segundo, eles são pensados, postos em relação, de sorte que existe para nós uma natureza submetida a uma ordem e a leis. 0 conhecimento tem assim condições "subjetivas", isto é, ligadas ao sujeito cognoscente. Como, então, considerar seu valor objetivo? Pelo fato de que o sujeito que faz um julgamento não é Pedro, Paulo ou Jaques - o conhecimento não varia com nenhum deles - mas é um sujeito 'transcendental': dito de outra forma, é o espírito humano em geral que está organizado desta forma e as condições do conhecimento são ao mesmo tempo subjetivas e as mesmas para todos (Clément et al., 1994, p. 190).

\section{Sobre o positivismo}

Nosso crítico pretende defender o positivismo nas ciências humanas. Não o neopositivismo do Círculo de Viena, nem as posturas críticas de Bertrand Russell em relação à defesa que se fez dos saberes não computáveis, como a psicologia, a psicanálise, as metafísicas contemporâneas que negam o olhar antigo, clássico, platônico. Essa mesma filosofia analítica que acolheu o primeiro Wittgenstein, mas que, no dizer do mesmo, "leu mas não entendeu nada".

Pois bem. Isso levou a um vício no julgamento do trabalho de outros, igualmente descartáveis, porque não seguiam o credo positivista: Onde estão as bases? Como você pode afirmar? Quem irá acreditar nisso?

Não se pode, numa única canetada, descartar eminentes pensadores com Husserl, Bergson, Merleau-Ponty, Jaspers, Levinas, Buber, toda uma escola de pensamento, como o Círculo Cibernético, enfim todos aqueles que refutam o empirismo, localizando nele falhas evidentes, como erro de captura e observação,

Dossiê Crise, Feminismo e Comunicação - https://revistaecopos.eco.ufrj.br/

ISSN 2175-8689 - v. 23, n. 3, 2020

DOI: 10.29146/eco-pos.v23i3.27646 
crença excessiva nos dados, ingenuidade em achar que basta ter os dados para ter a verdade,

A nova ciência antipositivista, nascida no século 19, desafia essas posturas e prova, eficientemente, que há sim verdade nas "novas ciências"; que o homem do século 19, o "observador", interfere no processo científico, que sua atuação no mundo pode não ser empiricamente comprovada o que não quer dizer que suas constatações não valham.

Essa mistificação do empírico levou a que a ciência contemporânea acabasse por debater a quem pertencia a herança do positivo, registrada na obra $A$ disputa do positivismo na sociologia alemã que resultou, como sabemos, nas contraposições de Popper, Feyerabend e Kuhn e de um saber instituído. E quem saiu perdendo foi o próprio positivismo, que teve que aceitar as teses que Rüdiger (2020) rejeita. Dizem:

- (Necessitamos de) uma teoria rígida, positiva

- Se não há partilha, como saber dela?

- Por que seria a comunicação sempre singular?

- A estética é algo transcendental

- Coletividade humana é um indicador (de quê?)

- Sua teoria é fraca e falaciosa

E como se dá a propagação e a divulgação desse novo saber? Não como o Sr. pensa, Sr. Rüdiger, não é assim que funciona. Isto não é um supermercado, onde cada autor está lá com seu banner, anunciando seu produto para quem quiser comprá-lo. Não sou eu quem sai atrás dos pesquisadores da área oferecendo um novo produto para ele poder testá-lo e validar sua eficácia.

Menos ainda, Sr. Rüdiger, trabalharia eu com a coletividade humana, conceito esse vago, impreciso e genérico. Eu aposto, ao contrário, nos leitores "afiados", categoria à qual o Sr. infelizmente não pertence, pois é a dos que sabem ler com atenção e cuidado para exatamente refinar sua acuidade intelectiva.

A comunidade humana, Rüdiger, não me interessa enquanto "massa", visto que não tem esse requisito. Não se trata de elitismo nem de apelo aos melhores, 
mas de uma certa opção por quem se dedica a uma tarefa árdua, que é a de ir fundo na teoria e nos conceitos, a de não se submeter à massa, mas de extrair dela aqueles que não a seguirão.

É nesse aspecto que a política de quotas é mais democrática. Ela traz à universidade exatamente aquelas mentes ricas e produtivas, que não teriam chance de outra maneira. 0 quotismo dá uma oportunidade a que o indivíduo saia da massa mesmo sendo pobre e sem formação, apelando apenas para sua sensibilidade, outra categoria que estaria riscada dos critérios rüdigerianos.

Não, ele foi mais longe. Foi buscar nas raízes comtianas a velha história do teológico, místico e, por fim, positivo. Naquele homem que até o fim da vida quis prestar homenagem à sua amada Clotilde de Vaux rezando, diante do túmulo, o mesmo credo eternamente. Bizarro que o defensor de uma ciência positiva, que renegou a teologia, tenha se voltado, no final de sua vida, um ritual de homenagem mística a uma mulher, desconsiderando o que poderia haver de mais antipositivo nessa atitude.

O velho positivismo, que dizia que a única forma de conhecimento verdadeiro seria científica, desconsiderou todas as demais formas de conhecimento humano, que ele chamava de metafísica ou teológica.

E, em relação à natureza, Sr. Rüdiger, olhá-la. Mas não basta olhar nem estudar o universo. O conhecimento oriental talvez consiga, desta maneira, desvendar segredos do universo. Mas aqui, no Ocidente, não praticamos a ciência com esse instrumental, que, apesar da ironia, eu respeito muito.

Dos filmes antigos não se entende, porque o Rüdiger não atribui valor ou validade para material cultural de outras épocas. Meus alunos trabalham com obras fílmicas feitas há 60 anos e têm condição de ver nelas processos revolucionários de conhecimento. Agora, suas fontes, caro Rüdiger, devem ser, então, sempre novas, porque se não for, então não funcionam. Mas, que lógica é essa? A de aplicar também aos produtos culturais o princípio da juventude? Desconheço.

Dossiê Crise, Feminismo e Comunicação - https://revistaecopos.eco.ufrj.br/ 
Para mim, uma obra do teatro grego clássico pode me fazer chorar, assim como um Shakespeare, Cervantes, Dante, mesmo Fausto ou Voltaire, estariam descartados? Talvez Rüdiger não tenha lido jamais a obra de Marcel Proust e mesmo a de Lewis Carroll, que me parecem mais atuais do que qualquer outra coisa.

Eu lhe aconselharia, se o Rüdiger me permite, é claro, ler as passagens de Gilles Deleuze (2009) sobre obras literárias que seriam mera "efetuação" em comparação com aquelas que efetivamente continuam a marcar a memória de gerações inteiras e que fazem o trabalho da contra-efetuação ( $O$ Anti-Édipo,de 1972). Talvez o Sr. pudesse aprender um pouco com isso.

\section{Conclusão}

Quando não se pode falar... Por fim, Rüdiger, me traz a famosa citação de Wittgenstein: Eu lhe confesso, foi o maior chute fora que o Sr. deu em todo seu texto. A frase, todos a conhecemos, diz que se não se pode falar, deve-se calar e o Sr. acha que cabe em sua "crítica" à minha Nova Teoria da Comunicação.

Mais uma vez, o Sr. perdeu, com isso, o caráter irônico do filósofo vienense. Em sua estada na Universidade de Cambridge, Wittgenstein escreveu seu Tractatus, que, como sabemos, foi superado pela obra seguinte, póstuma, Investigações filosóficas. Em sua defesa oral da tese, Russell ficou decepcionado, parece que Wittgenstein teria feito uma brincadeira com ele. A banca que o examinou neste segundo exame teve verdadeiras dificuldades em avaliá-lo. Mas o filósofo já estava com um pé fora da universidade dizendo que o que teria que ser dito em filosofia já fora dito.

Mas, vamos ao que interessa. Wittgenstein, em carta a seu editor L. von Ficker revelou que a frase estava incompleta.

[...] Certa vez, pensei em incluir no prefácio uma proposição que agora não está lá, mas que escreverei neste momento para o senhor, porque talvez constitua para o senhor uma chave para a compreensão do trabalho. Com

Dossiê Crise, Feminismo e Comunicação - https://revistaecopos.eco.ufri.br/

ISSN 2175-8689 - v. 23, n. 3, 2020

DOI: 10.29146/eco-pos.v23i3.27646 
efeito, eu queria escrever que o meu trabalho consiste em duas partes: aquilo que eu escrevi e, ademais, tudo aquilo que eu não escrevi. E precisamente esta segunda parte é importante [...]. Ou seja, o que não está escrito, o que não é dito porque não é dizível cientificamente é que constitui o mais importante (REALE, 1991, p. 661).

Não era apenas o "se não é possível falar, então que se cale" ou, para letrados com o Sr Rüdiger., "was sich überhapt sagen lässt, lässt sich klar sagen, und was man nicht sagen kann, darüber muss schweigen". Ao seu editor, ao contrário, ele confessou que o verdadeiro sentido estava na continuação, que era a parte mais importante: a ética e a religião.

Veja-se igualmente Engelmann:

Toda uma geração de alunos considerou Wittgenstein positivista, já que ele tinha em comum com os positivistas algo de enorme importância: ele traçara uma linha de separação entre aquilo de que se pode falar e aquilo que se deve calar, coisa que os positivistas também haviam feito. A diferença está apenas no fato de que eles não tinham nada sobre o que calar. O positivismo sustenta - e essa é sua essência - que aquilo de que podemos falar é tudo o que conta na vida. Já Wittgenstein crê apaixonadamente que tudo o que conta na vida humana é precisamente aquilo sobre o qual, no seu modo de ver, devemos calar. Apesar disso, quando ele dedica um imenso cuidado a delimitar o que não é importante, não é a costa daquela ilha que ele quer examinar mais acuradamente, e sim os limites do oceano

Lamento, meu caro, mas isso derruba toda sua escrita. Você também não entendeu nada.

\section{Referências bibliográficas}

ALTHUSSER, L. Resposta a John Lewis. Lisboa: Editorial Estampa, 1973.

ANDERS, Günther. Die Antiquiertheitdes Menschen 2: über die Zerstörung des Lebens im Zeitalter der dritten industriellen Revolution. Munique: C. H. Beck, 1980.

BENJAMIN, Walter. A obra de arte na época de sua reprodutibilidade técnica. Tradução Francisco Dea Ambrosis Pinheiro Machado. Porto Alegre: Zouk, 2012.

Dossiê Crise, Feminismo e Comunicação - https://revistaecopos.eco.ufrj.br/

ISSN 2175-8689 - v. 23, n. 3, 2020

DOI: 10.29146/eco-pos.v23i3.27646 
BERGSON, Henri. A Evolução Criadora. São Paulo: Unesp, 2009.

Clément, E. et al. La philosophie de A à Z. Hatier, Paris,1994.

DELEUZE, Gilles. A Imagem-Movimento Cinema 1. Lisboa: Assírio \& Alvim, 2009.

DERRIDA, Jacques, Soussana, G.; NOUSS, A. [2001]. Decir el acontecimiento. Es posible? Tradução Julián Santos Guerrero. Arena Libros, Madri, 2006.

Gil, José. A imagem nua e as pequenas percepções. Estética e metafenomenologia. Tradução. Miguel Serras Pereira. 2. ed. Lisboa: Relógio D’Água Editores, 2005.

HEIDEGGER, Martin. Der Fehl heiliger Namen: Le défaut des noms sacrés. Éd. Gramma, 1981.

KANT, I. Crítica da faculdade do Juízo. Tradução Valério Rohden e Antônio Marques. Rio de Janeiro: Forense, 2008.

KENNEDY, Barbara. [2002]. Deleuze and Cinema. The Aesthetics of Sensation. Edinburg, Edinburg Univ. Press, 2002.

LUHMANN, Niklas. A realidade dos meios de comunicação. São Paulo: Paulus, 2005.

MARCONDES F., Ciro. Princípio da Razão Durante: por uma teoria do acontecimento em comunicação. São Paulo: Paulus, 2008.

NIETZSCHE, Friedrich. Crepúsculo dos ídolos, ou, como se filosofa com o martelo. Tradução, notas e posfácio Paulo César de Souza. São Paulo: Companhia das Letras, 2006.

MERLEAU-PONTY, M. Le visible et l'invisible. Paris: Gallimard, 1996.

OLIVEIRA, Danielle Naves de. Poros, ou as passagens da comunicação. São Paulo: Paulus, 2016. 
REALE, Giovanni.; ANTISERI, Dario. História da filosofia: do humanismo a Descartes. São Paulo: Paulus, 1991. v. 3.

ROMANO, Claude. Lo posible y el acontecimiento. Introducción a la Herméutica Acontecial. Tradução Aníbal Fornari, Patrício Mena e Enoc Muñoz. Ediciones Univ. Alberto Hurtado, Santiago, 2008.

SERRES, Michel. Os cinco sentidos. Filosofia dos corpos misturados. Tradução. Eloá Jacobina. Rio de Janeiro: Bertrand Brasil, 2001. 